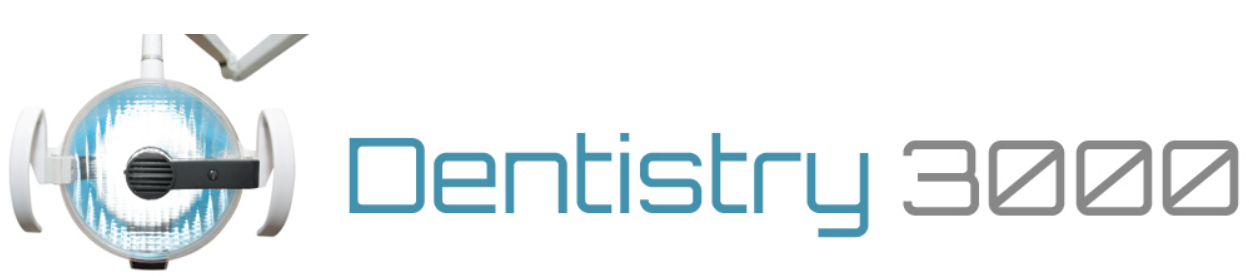

\title{
Prevalence of dental anomalies in a Mexican population
}

\author{
Jose R. Herrera-Atoche ${ }^{1}$, Silvia M. Diaz-Morales ${ }^{1}$, Gabriel E. Colomé-Ruiz ${ }^{1}$, Mauricio Escoffié-Ramírez ${ }^{1}$, María Fernanda Orellana ${ }^{2}$. \\ ${ }^{1}$ Universidad Autónoma de Yucatán, Faculty of Dentistry, Orthodontic Department \\ ${ }^{2}$ University of California San Francisco, School of Dentistry, Department of Orofacial Sciences
}

\section{Abstract}

Background: Data on dental anomaly prevalence is instrumental to diagnosis and treatment in different populations. A retrospective study was done to determine dental anomaly prevalence and associations in a group of orthodontic patients in a Mexican population. Methods: Number, shape, eruption and structural dental anomalies were assessed from the records of 670 subjects. Prevalence, distribution, and associations between the different anomalies were calculated. Chi-squared and Fisher's exact tests $(p<0.05)$ were used to identify significant differences by sex, and to establish associations among the studied anomalies. Results: Twenty-eight percent of the sample exhibited at least one dental anomaly. Statistical analysis identified no differences by gender. The most common anomaly was impacted teeth (13.58\%), followed by microdontic upper lateral incisors (6.26\%). These two anomalies also had the highest number of significant associations with other anomalies. Conclusions: The dental anomalies prevalence documented here differ from those reported in the literature for other populations in the world. Dental anomalies are normally associated with each other and occur in groups linked to ethnic origin. The present results indicate the presence of differing suites of anomalies between the studied Mexican population and other populations in the world. This variation highlights the need for further research on dental anomalies in Latin America to aid in their diagnosis and treatment.
Citation:Herrera-Atoche JR, Diaz-Morales SM, Colomé-Ruiz GE, Escoffié-Ramírez $M$, and Orellana MF. (2014) The prevalence of dental anomalies in a Mexican population. Dentistry 3000. 1:a001 doi:10.5195/d3000.2014.25

Received: June 16, 2014

Accepted: November 24, 2014

Published: December 10, 2014

Copyright: (C)2014 Herrera-Atoche et al. This is an open access article licensed under a Creative Commons Attribution Work 4.0 United States License.

Email: jose.herrera@uady.mx

\section{Introduction}

Dental anomalies (DA) can represent a challenge for attaining ideal occlusion and esthetics in dentition. Absence, atypical location and abnormal tooth shape often require interdisciplinary treatment involving orthodontics, surgery and/or oral rehabilitation. Prevalence of DA worldwide varies [1-5], probably due primarily to genetic variation between ethnicities. There is evidence about the association between different types of DA within populations of the same ethnicity [6-10]. For example, subjects with unilateral peg-shaped maxillary permanent lateral incisors can have up to a $55 \%$ probability of exhibiting lateral incisor agenesis on the contralateral side [11]. Other examples include a study of Japanese subjects with agenesis of one or two permanent mandibular lateral incisors, which had significantly increased prevalence rates of other permanent tooth agenesis and symmetrical dental agenesis [12], and a relation between third molar agenesis and impacted canines in a Portuguese population [13].

Several studies have addressed DA in different populations. In Latin America, there are a number of studies of isolated DA, but reports documenting various DA in a Latino population are rare. One example is a reported $2.5 \%$ DA prevalence in primary dentition (2-5 year-old children) in a Brazilian population, which the authors stated is higher than in other populations [14]. Given the sample age range and the small number of studied DA, it is probable that DA prevalence in an older population would vary more broadly.

Malocclusion and aesthetic problems are only some of the problems caused by DA. Data on DA prevalence and associations is vital to diagnosis of dental disorders and treatment planning. The objective of the present study was to document DA preva- lence and association in orthodontic patients in a Mexican population.

\section{Materials and Methods}

A retrospective study was done of a sample of 690 records for orthodontic patients examined by three calibrated orthodontists. Records were from the orthodontic clinic archives at the Autonomous University of Yucatan (Universidad Autónoma de Yucatan - UADY), Merida, Yucatan, Mexico. Patient age ranged from 9 to 20 years of age. All patients were of Mexican origin. Subjects with a history of trauma, prior orthodontic treatment, cleft lip and palate or other syndromes were excluded. Incomplete or inadequate records lacking quality data (e.g. photographs, dental casts, $x$-rays, etc.) were eliminated. Following these criteria, 20 patients were eliminated from the sample. Of the remaining 670 subjects, $65.38 \%$ were female $(n=438)$ and $34.62 \%$ male $(n=232)$

A total of 12 DA were assessed:

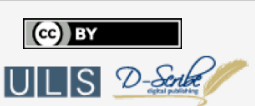


1. Dental agenesis. Dental agenesis was diagnosed when "no mineralization of tooth crown could be identified on orthopantomograms or a full-mouth set of periapical radiographs, and no evidence of its having been extracted was found" [15]. Third molars were excluded.

2. Supernumerary teeth (SNT). A tooth was considered as supernumerary when "it appears in addition to the regular number of teeth" [2].

3. Microdontic upper lateral incisors (MULI). Diagnosed when an upper lateral incisor presents "mesio-distal width equal to or smaller than that of its mandibular counterpart" [7]. The measurements were made with a Mitutoyo digital caliper (Aurora, Illinois, USA).

4. Peg-shaped upper lateral incisors (PSULI). An upper lateral incisor was classified as peg-shaped when "mesio-distal width was greatest at the cervical margin" [7].

5. Barrel-shaped upper lateral incisors (BSULI). An upper lateral incisor was classified as barrel-shaped when a "pronounced manifestation of a thickened or elevated cingulum was found on the gingival aspect of lingual surfaces" [16].

6. Upper lateral incisors with talon cusp (TC). TC was defined as an "accessory cusplike structure that projects from the cingulum area or cementoenamel junction" [17].

7. Fusion. This was diagnosed "if [tooth] crown and root were enlarged and tooth count revealed a missing tooth" [18].

8. Gemination. A tooth was considered to have gemination if its "crown was enlarged with a normal root and the tooth count was normal" [18].

9. Impacted teeth (IT). A tooth was considered impacted when "it was not expected to erupt completely into its normal functional position based on clinical and radiographic assessments" [2]. Third molars were excluded.

10. Transposition. This was defined as "the positional interchange of two adjacent teeth, or the development or eruption of a tooth in a position normally occupied by a non-adjacent tooth" [8].

11. Transmigration. A tooth was considered to be in a transmigrated position when "the eruption path had been altered and the tooth had drifted to the opposite side of the arch with at least half of the crown length crossing the midline" [19].

12. Amelogenesis imperfecta (AI). This structural anomaly "represents a group of developmental conditions, genomic in origin, which affect the structure and clinical appearance of enamel of all or nearly all the teeth in a more or less equal manner, and which may be associated with morphologic or biochemical changes elsewhere in the body" [20]. No subgroups were distinguished for the present study.

\section{Statistical analysis}

Once the DA-positive population was identified, DA prevalence and distribution were calculated. A Chi-squared test or Fisher's exact test were used to identify any differences between sexes and any associations between the different DA ( $P<0.05)$.

\section{Results}

Of the 670 subjects, $28.05 \%(n=188)$ exhibited at least one dental anomaly. Distribution by gender was $62.76 \%(n=118)$ in females and $37.23 \%(n=70)$ in males, with no differences ( $p>0.05)$ in frequency. The most prevalent DA was IT $(13.58 \%$; $n=91)$, followed by MULI (6.26\%; $n=42)$ (Table 1 ).

\section{Number of anomalies}

Dental agenesis was present in 5.82\% $(n=39)$ of the subjects. A total of 66 cases of absent teeth were identified, 47 (71.21\%) of which were a lower tooth. The most commonly absent tooth was the second lower premolar $(25.75 \%, \mathrm{n}=17)$ followed by the lower lateral $(22.72 \%, n=15)$. In the maxillary arch, the most frequently absent teeth were the lateral incisors $(10.60 \%, \mathrm{n}=7)$ and the second molars $(10.60 \%, \mathrm{n}=7)$. A total of $40(5.97 \%)$ SNT were identified, 33 of which were in the upper arch (73.33\%); mesiodens were the most common SNT $(n=19)$.

\section{Shape anomalies}

The most frequent shape anomaly was MULI (6.26\%; $n=42)$. Of these 42 subjects, 18 had bilateral affectation, raising the overall MULI total to 60. A total of $29(48.33 \%)$ cases were on the right side and 31 $(51.66 \%)$ on the left. Ten $(1.49 \%)$ PSULI cases were identified; five patients presented bilaterally, producing an overall total of 15 PSULI teeth (9 left/6 right). Prevalence for BSULI was $2.83 \%(n=19)$; two cases were bilateral, for a total of 21 affected teeth (11 left, 10 right). Upper lateral incisors with TC were found in 7 (1.04\%) cases; the right side was most affected $(n=5)$, and no bilateral affectations were identified Only two male patients exhibited fusion $(0.3 \%)$. In one case, the lower right lateral and central incisor were affected and in the other the lower central incisors were involved. No gemination cases were present in the sample.

\section{Eruption anomalies}

Prevalence for IT was $13.58 \%(n=91)$, although the total number of teeth exhibiting IT was 123: 96 in the upper arch (78.05\%) and 27 in the lower (21.95\%). The most affected tooth was the upper canine (48.78\%; $n=60)$, followed by the upper central incisor and the upper second premolar (13.01\%; $\mathrm{n}=16$ in both cases). Transposition was noted in 16 cases $(2.38 \%)$ and was present only in the maxillary arch. Bilateral transposition was present in three patients, raising the total to 19 teeth. Transposition of the upper canines and laterals was the most common (10 cases, five per side). This next most common configuration was transposition of the upper canine with the first premolar (8 cases, four per side). In only one case, the upper canine had transposed with the second premolar on the right side.

Just one $(0.14 \%)$ subject (female) exhibited transmigration; in this case, of the lower right canine.

\section{Structural anomalies}

Three female subjects exhibited AI (0.44\%).

No differences $(p>0.05)$ by gender were identified for any of the studied DA. Nine significant $(p<0.05)$ associations were found between different DA: IT with dental agenesis, SNT, MULI, BSULI and transposition; MULI with PSULI, BSULI and transposition; and transposition with BSULI (Table 2). 
Table 1. Prevalence and distribution of dental anomalies by sex in a group of 670 patients.

\begin{tabular}{lcccccc}
\hline \multicolumn{1}{c}{$\begin{array}{c}\text { Dental } \\
\text { Anomalies }\end{array}$} & $\begin{array}{c}\text { Male } \\
\mathrm{n}=232(34.62 \%)\end{array}$ & $\begin{array}{c}\text { Female } \\
\mathrm{n}=438(65.38 \%)\end{array}$ & $\begin{array}{c}\text { Total } \\
\mathrm{n}=670(100 \%)\end{array}$ & $p$ & $\begin{array}{c}\text { Male } \\
\text { Risk/Ratio }\end{array}$ & $\begin{array}{c}\text { Female } \\
\text { Risk/Ratio }\end{array}$ \\
\hline Agenesis & $14(2.09)$ & $25(3.73)$ & $39(5.82)$ & 0.863 & 1.06 & 0.95 \\
SNT & $18(2.69)$ & $22(3.28)$ & $40(5.97)$ & 0.157 & 1.54 & 0.65 \\
MULI & $16(2.38)$ & $26(3.88)$ & $42(6.26)$ & 0.625 & 1.16 & 0.86 \\
PSULI & $4(0.6)$ & $6(0.89)$ & $10(1.49)$ & 0.719 & 1.26 & 0.79 \\
BSULI & $6(0.89)$ & $13(1.94)$ & $19(2.83)$ & 0.777 & 0.87 & 1.15 \\
Upper laterals with TC & $5(0.74)$ & $2(0.3)$ & $7(1.04)$ & 0.062 & 4.72 & 0.21 \\
Fusion & $2(0.3)$ & $0(0.00)$ & $2(0.3)$ & - & - & - \\
Gemination & $0(0.00)$ & $0(0.00)$ & $0(0.00)$ & - & - & - \\
IT & $31(4.63)$ & $60(8.95)$ & $91(13.58)$ & 0.903 & 0.96 & 1.03 \\
Transposition & $7(1.04)$ & $9(1.34)$ & $16(2.38)$ & 0.439 & 1.49 & 0.68 \\
Transmigration & $0(0.00)$ & $1(0.14)$ & $1(0.14)$ & - & - & - \\
Al & $0(0.00)$ & $3(0.44)$ & $3(0.44)$ & - & - & - \\
\hline
\end{tabular}

:Abbreviations: (STN) Supernumerary Teeth; (MULI) Microdontic upper lateral incisors; (PSULI) Peg-shaped upper lateral incisors; (BSULI) Barrel-shaped lateral incisors; (TC) Talon cusp; (IT) Impacted teeth; (AI) Amelogenesis imperfecta

\section{Discussion}

Overall DA prevalence in the sample was $28.05 \%(n=188)$. Prevalence rates reported in different studies range from $5.46 \%$ to $74.77 \%[1-5,21]$, but the present results were nearest those reported for a population in Egypt [21]. This high variation in prevalence values may be due to differences in sample sizes, nature of the sample (orthodontic, dental, or general population), and the number and type of anomalies studied. However, exclusion of eruption and position anomalies substantially reduces these prevalence rates. In the present sample, no difference $(p>0.05)$ in prevalence was present between genders. The most prevalent DA was IT $(13.58 \%$; $n=91)$, followed by MULI (6.26\%; $n=42)$.

\section{Number of anomalies}

Dental agenesis prevalence was $5.82 \%$ $(n=39)$, within the 2.7 to $13.3 \%$ range reported worldwide [1,3-5,15,22-25]. In previous reports on Mexican populations, $2.7 \%$ [22] and 4.5\% [23] prevalence was observed. The difference between the present results and these studies may be at least partially due to genetic variation between populations in different regions of Mexico [26]. The most frequently absent tooth was the lower second premolar, which concurs with other reports $[1,15,25]$. In the present sample, dental agenesis was associated with IT $(\mathrm{p}=0.023)$, an association reported elsewhere $[9,10,24]$, and possibly linked to shared genetic origins.
Global SNT prevalence varies from 0.3 to $6 \%$ [1,2,4,27-30]. The prevalence observed in the present sample (5.97\%) is similar to that reported in an African-American population [27]. Of note is that SNT prevalence in the African-American population was higher in the molar and premolar regions, while in the present study it was higher in the maxillary anterior region, which is similar to other reports $[1,2,4,28-30]$. It can be expected that, since SNT tends to block the eruption path of other teeth, it was statistically associated with IT $(\mathrm{p}=0.008)$. For this same reason, this association appears to be more related to the eruption path and not necessarily of genetic origin.

\section{Shape anomalies}

Comparison of microdontic teeth between studies can be challenging since each report tends to quantify them differently; some include just the upper laterals [6], others the upper and lower laterals [4], others include all teeth [2], etc. In previous reports, MULI ranges from as low as $2.58 \%$ to the $6.26 \%$ reported in the present study $[3,5,6]$. Associations were found between MULI and four other DA in the present study (Table $2)$. The associations with IT $(p=0.0007)$ coincide with previous reports [6,31], as does that with dental transposition $(\mathrm{p}=0.002)$ [32].

Prevalence for PSULI was $1.49 \%$, which is within the 0.37 to $9.9 \%$ range of previously reported values $[1,5,33]$. If differences due to ethnicity are excluded, this high variabil- ity may be heavily influenced by sample size; indeed, the larger the sample size the lower the prevalence. As expected, PSULI was associated with microdontia $(\mathrm{p}=0.0001)$.

Worldwide, BSULI is normally associated with East Asian populations, although its prevalence in this study was higher than that reported for a sample from China [16]. In the present results, prevalence for this DA was higher than other upper lateral incisor shape anomalies. This is interesting because peg-shaped or TC teeth are studied more frequently than barrel-shaped anomalies, which are not commonly reported. The statistical associations observed here between BSULI and other DA, such as IT $(\mathrm{p}=0.008)$ and transposition $(\mathrm{p}=0.0001)$, imply genetic causes. As with PSULI, BSULI was associated with microdontia $(\mathrm{p}=0.0001)$. Further research in Latin American populations would aid in supporting these associations and identifying their distribution in the region.

Fused teeth were present in only $0.3 \%$ of subjects, a prevalence similar to those reported in Indian $(0.27 \%)$ [5] and Turkish populations $(0.23 \%)$ [4].

\section{Eruption anomalies}

The $13.58 \%(n=91)$ prevalence for IT in the present study made it the most prevalent DA in the study. This prevalence is similar to that reported for a Greek population [30], and at the high end of the 0.49 to $13.7 \%$ range reported in the literature 
$[1,2,5,19,30]$. Variations can be explained as a consequence of sample nature, subject ethnicity, and sample size. Despite this wide value range among studies, all the reports concur in that the upper canine is the most er populations in the world. The most prevalent DA were IT and MULI, and these also had the highest number of significant associations with other DA. Given that dental anomalies are primarily of genetic origin,

9. Agenesis of maxillary lateral incisors and associated dental anomalies. Garib DG, Alencar BM, Lauris JR, Baccetti T. Am J Orthod Dentofacial Orthop. 2010 Jun;137(6):732.e1-6. PMID: 20685523.

10. Maxillary palatal canine impaction displacement in subjects with congenitally missing maxillary lateral incisors. $\mathrm{Al}$ Nimri KS, Bsoul E. Am Orthod Dentofacial Orthop. 2011 Jul;140(1):81-6. PMID: 21724091.

11. Prevalence of pegshaped maxillary permanent lateral incisors: A meta-analysis. Hua $\mathrm{F}$, He H, Ngan P, Bouzid W. Am J Orthod Dentofacial Orthop. 2013 Jul;144(1):97-109. PMID: 23810051.

12. Association of agenesis of mandibular lateral incisors with other dental anomalies in a

frequently impacted tooth $[1,2,5,19,30]$. As mentioned previously, when SNT is present impaction is an apparent consequence, whereas its association with other DA (MULI, BSULI, transposition, and dental agenesis) is more probably of genetic origin $[6,7,10,31]$.

The prevalence rate of transposition was relatively high $(2.38 \%)$ compared to other reports: $0.27 \%$ [34], $0.33 \%$ [35], and $0.81 \%$ [32]. However, the present data coincides with these previous studies in that the unilateral presentation is the most common, and that the maxillary arch is the most affected [34-36]. As reported elsewhere [34], all transposition cases in the present sample involved the canine teeth. Several DA are reported to be associated with transposition $[32,34,36]$. The DA associated with transposition (MULI, BSULI, IT) in the present results suggest a genetic origin for this phenomenon

Only one female patient exhibited transmigration in the mandible. This is consistent with a report that the most common occurrence of canine transmigration is in the lower arch in women [19].

\section{Structural anomalies}

The $0.44 \%$ AI prevalence observed in the present data is very near the $0.43 \%$ prevalence reported for a Turkish population [4], and only slightly higher than the $0.27 \%$ prevalence found in an Indian population [5].

The DA prevalence documented in this orthodontic population from Mexico varied in many respects from those reported for oth- this prevalence vary widely between ethnicities. Little DA data is available for Latin American populations, further research in the region is clearly needed to advance the ability of dental health professionals to diagnose and effectively treat these disorders.

\section{References}

1. Prevalence of dental anomalies in orthodontic patients. Thongudomporn U, Freer TJ. Aust Dent J. 1998 Dec;43(6):395-8. PMID: 9973708.

2. Prevalence of dental anomalies in various malocclusions. Uslu O, Akcam MO, Evirgen S, Cebeci I. Am J Orthod Dentofacial Orthop. 2009 Mar;135(3):328-35. PMID: 19268831.

3. Evaluation of the Prevalence of Dental Anomalies in Children in the Canton of Sarajevo. SpahićDizdarević M, Deljo E, Ganibegović-Selimović M. Acta Stomatol Croat. 2011;45(1):24-30.

4. Prevalence and distribution of dental anomalies in orthodontic patients. Altug-Atac AT, Erdem D. Am J Orthod Dentofacial Orthop. 2007 Apr;131(4):510-4. PMID: 17418718.

5. Prevalence and distribution of selected developmental dental anomalies in an Indian population. Gupta SK, Saxena P, Jain S, Jain D. J Oral Sci. 2011;53(2):231-8. PMID: 21712629.

6 . A controlled study of associated dental anomalies. Baccetti T. Angle Orthod. 1998 Jun;68(3):267-74. PMID: 9622764.

7. The incidence of anomalous maxillary lateral incisors in relation to palatally-displaced cuspids. Becker A, Smith P, Behar R. Angle Orthod. 1981 Jan;51(1):24-9. PMID: 6939351.

8. Maxillary canine-first premolar transposition, associated dental anomalies and genetic basis. Peck L, Peck S, Attia Y. Angle Orthod. 1993 Summer;63(2):99-109. PMID: 8498708.
Japanese population. Endo S, Sanpei S, Takakuwa A, Takahashi K, Endo T. J Dent Child (Chic). 2013 Jan-Apr;80(1):9-15. PMID: 23595238.

13. Dental anomalies in a Portuguese population. Campoy MD, González-Allo A, Moreira J, Ustrell J Pinho T. Int Orthod. 2013 Jun;11(2):210-20. PMID: 23541047.

14. Dental anomalies and associated factors in 2 to 5-year-old Brazilian children. Kramer PF, Feldens CA, Ferreira SH, Spiguel MH, Feldens EG. Int J Paediatr Dent. 2008 Nov;18(6):434-40. PMID: 18435724

15. A survey of hypodontia in Japanese orthodontic patients. Endo T, Ozoe R, Kubota M, Akiyama M, Shimooka S. Am J Orthod Dentofacial Orthop. 2006 Jan;129(1):29-35. PMID: 16443475.

16. Incisal morphology of southern Chinese. Ling JYK, Wong RWK. Open Anthropol J. 2008;1:19-25.

17. Talon cusp-clinical significance and management: case reports. Hattab $\mathrm{FN}$, Yassin $\mathrm{OM}$, alNimri KS. Quintessence Int. 1995 Feb;26(2):115 20. PMID: 7568721

18. Prevalence of fused and geminated teeth in Jordanian adults. Hamasha AA, Al-Khateeb $\mathrm{T}$. Quintessence Int. 2004 Jul-Aug;35(7):556-9. PMID: 15259971.

19. The incidence of canine transmigration and tooth impaction in a Turkish subpopulation. Ak$\tan$ AM, Kara S, Akgunlu F, Malkoc S. Eur J Orthod. 2010 Oct;32(5):575-81. PMID: 20237077.

20. Amelogenesis imperfecta. Crawford PJ, Aldred M, Bloch-Zupan A. Orphanet J Rare Dis. 2007 Apr 4;2:17. PMID: 17408482.

21. Prevalence and distribution of dental anomalies in orthodontic patients. Montasser MA, Taha M. Orthodontics (Chic). 2012;13(1):52-9. PMID: 22567616

22. Radiographic assessment of congenitally missing teeth in orthodontic patients. Silva Meza 
R. Int J Paediatr Dent. 2003 Mar;13(2):112-6. PMID: 12605629.

23. Agenesis in permanent dentition. Díaz-Pérez R, Echaverry-Navarrete RA. Rev Salud Pública (Bogota). 2009 Dec;11(6):961-9. PMID: 20379669.

24. Prevalence of hypodontia in orthodontic patients in Brasilia, Brazil. Gomes RR, da Fonseca JA, Paula LM, Faber J, Acevedo AC. Eur J Orthod. 2010 Jun;32(3):302-6. PMID: 19837747.

25. Survey on hypodontia in Sayada, Tunisia. Maatouk F, Baaziz A, Ghnima S, Masmoudi F, Ghedira H. Quintessence Int. 2008 Mar;39(3):e115-20. PMID: 18618026.

26. Analysis of genomic diversity in Mexican Mestizo populations to develop genomic medicine in Mexico. Silva-Zolezzi I, Hidalgo-Miranda A, Estrada-Gil J, Fernandez-Lopez JC, Uribe-Figueroa L, Contreras A, Balam-Ortiz E, del Bosque-Plata L, Velazquez-Fernandez D, Lara C, Goya R, Hernandez-Lemus E, Davila C, Barrientos E, March S, Jimenez-Sanchez G. Proc Natl Acad Sci USA. 2009 May 26;106(21):8611-6. PMID: 19433783.

27. An epidemiological study of hyperdontia in American blacks and whites. Harris EF, Clark LL. Angle Orthod 2008 May;78(3):460-5. PMID: 18416616.

28. Supernumerary teeth vary depending on gender. Küchler EC, Costa AG, Costa Mde C, Vieira AR, Granjeiro JM. Braz Oral Res. 2011 JanFeb;25(1):76-9. PMID: 21359454

29. Supernumerary teeth in a Turkish population. Esenlik E, Sayin MO, Atilla AO, Ozen T, Altun C, Basak F. Am J Orthod Dentofacial Orthop. 2009 Dec;136(6):848-52. PMID: 19962608.

30. Incidence of impacted and supernumerary teeth-a radiographic study in a North Greek population. Fardi A, Kondylidou-Sidira A, Bachour Z, Parisis N, Tsirlis A. Med Oral Patol Oral Cir Bucal. 2011 Jan 1;16(1):e56-61. PMID: 20711166.

31 . The palatally displaced canine as a dental anomaly of genetic origin. Peck S, Peck L, Kataja M. Angle Orthod. 1994;64(4):249-56. PMID: 7978519.

32. A retrospective study on 69 cases of maxillary tooth transposition. Cho SY, Chu V, Ki Y. J Oral Sci. 2012;54(2):197-203. PMID: 22790413.

33. Variations in number and morphology of permanent teeth in 7-year-old Swedish children. Bäckman B, Wahlin YB. Int J Paediatr Dent. 2001 Jan;11(1):11-17. PMID: 11309867.

34. Investigation of tooth transposition in a nonsyndromic Turkish anatolian population: characteristic features and associated dental anomalies. Celikoglu M, Miloglu 0, Oztek O. Med Oral Patol Oral Cir Bucal. 2010 Sep 1;15(5):e716-20. PMID: 20173710.

35. Prevalence of tooth transposition. A metaanalysis. Papadopoulos MA, Chatzoudi M, Kaklamanos EG. Angle Orthod. 2010 Mar;80(2):275-85. PMID: 19905852.

36. Dental transposition as a disorder of genetic origin. Ely NJ, Sherriff M, Cobourne MT. Eur J Orthod 2006 Apr;28(2):145-51. PMID: 16373452. 